\title{
PREDICTING ORGANIZATIONAL COMMITMENT THROUGH ORGANIZATION CULTURE: A STUDY OF AUTOMOBILE INDUSTRY IN INDIA
}

\author{
Kavita Singh \\ Faculty of Management Studies, University of Delhi, 110007 Delhi, India \\ Phone: $O$ - 91-11-27667017/419/002, $R-91-11-27666500$ \\ Fax:91-11-27667183,E-mail: kavitas22@gmail.com; ksingh22@rediffmail.com \\ Received 10 October 2006; accepted 12 December 2006
}

\begin{abstract}
The extent to which the employees of an organization feel committed to their organization can be easily gathered from the strength of its culture. This points out that even though the culture is holistic, it can be strengthened by commitment. Culture can be managed by managing the employees of the organization and also by leader's actions and interventions and these are also understood as the targets of management of commitment. Management of commitment is also the management of culture, as it is commitment that binds people to organization's ideas and agents. With these notions in mind, the present study makes an attempt, firstly, to integrate different conceptual constructs of commitment and culture and secondly, to identify the relationship between organizational commitment and organization culture.

The study is based on a sample of 382 executives from five automobile companies. The findings indicate that most of the dimensions of organizational culture are positively and significantly related to the dimensions of organizational commitment. Some of the dimensions of culture also made significant contribution to predict organizational commitment. The main issue that emerges from this study is that the importance of organizational culture in understanding organizational commitment can neither be underestimated nor overlooked.
\end{abstract}

Keywords: organizational culture, India, automobile industry.

\section{Introduction}

The term 'commitment' is widely used in sociology, psychology, and organization studies. Definitions and usage of the term emphasizing values, norms, affects, attachments, identification, and so on imply that it shares some of its referents with that of organizational culture. Weiner (1982) contends that the existing models of commitment do not satisfy the requirements of definitional precision, theoretical integration, and predictive power. Morrow's (1983) analysis reveals that, different concepts related to commitment are partially redundant and insufficiently distinct. Allen and Mayer (1990) state that the "use of term 'commitment' to describe very different constructs has led to considerable confusion in the literature." The purpose of this article is:

(a) To integrate different conceptual constructs of organizational commitment and culture.

(b) To identify how organizational commitment is related to organizational culture.

\section{Organizational commitment}

In the context of organizations, commitment is normally understood as different ways to commit oneself to an organization of which one is a member (see Table 1 for major definitions).

According to Becker's side-bet theory of commitment, the committed person's involvement in an organization can make side bets for him or her and constrain his or her future behaviour. When these constraints lead to behaviour that is consistent with the goals and values of the organizations, the individual is committed to the organization. Organizational commitment has also been defined as an individual's identification with and involvement in an organization (Porter, Steers, \& Mowday, 1974). In this view, commitment is characterized by a strong belief in and acceptance of the organization's goals and values, a willingness to exert considerable effort on behalf of the organization, and a strong desire to maintain membership in the organization. 
Table 1. Definitions of Commitment in the Context of Organizations

Becker (1960): "The committed person has acted in such a way as to involve other interests of his, originally extraneous to the action he is engaged in, directly in that action").

Kanter (1968): "Commitment...refers to the willingness of social actors to give their energy and loyalty to social systems, the attachment of personality systems to social relations which are seen as self-expressive".

Porter et al. (1974): Organizational commitment is defined "in terms of the strength of an individual's identification with and involvement in a particular organization. Such commitment can be characterized by at least three factors: (a) a strong belief in and acceptance of the organization's goals and values; (b) a willingness to exert considerable effort on behalf of the organization; (c) a definitive desire to maintain organizational membership".

Wiener (1982): "Organizational commitment is viewed as the totality of internalized normative pressures to act in a way that meets organizational goals and interests".

Reichers (1985): "Commitment is a process of identification with the goals of an organization's multiple constituencies. These constituencies may include top management, customers, unions, and/or the public at large".

O'Reilly and Chatman (1986): "Organizational commitment is conceived of as the psychological attachment felt by the person for organization; it will reflect the degree to which the individual internalizes or adopts characteristics or perspectives of the organization".

Meyer and Allen (1997): "Affective commitment refers to the employee's emotional attachment to, identification with, and involvement in the organization. Employees with a strong affective commitment continue employment with the organization because they want to do so. Continuance commitment refers to an awareness of the costs associated with leaving the organization. Employees whose primary link to the organization is based on continuance commitment remain because they need to do so. Finally, normative commitment reflects a feeling of obligation to continue employment. Employees with a high level of normative commitment feel that they ought to remain within the organization".

O'Reilly and Chatman (1986) understand organizational commitment as psychological attachment to the organization. Following Kelman (1958), they differentiate among three bases of commitment: (a) compliance, or "instrumental involvement for specific extrinsic rewards"; (b) identification, or "involvement based on a desire for affiliation"; and (c) internalization, or "involvement predicated on congruence between individual and organizational values." Virtanen (2000) prefers a trichotomy of obligations, utilities, and emotions. Emotions as bases of commitment constitute mostly arational bindings through the process of identification. They are "beyond reasons," not irrational (as the opposite of rational). Obligations and utilities as bases of commitment constitute mostly rational bindings through the mechanism of compliance and internalization.

The focus of commitment tells us about the content of commitment. The focus of commitment can be, for example, moral, legal, economic and political - in some cases even aesthetic. The foci of commitment are in many ways related to societal institutions, because they have a profound affect on how we see the world. Together with the bases of commitment, foci provide the motive of commitment as it is experienced.

The source of commitment tells us about the background from which different objects, loci, bases, and foci of commitment are generated. There may be many alternatives: education, training, leadership style and management systems, institutions, socioeconomic class, national culture, and civilizations. These are all responsible for diverse content of commitments.

Antecedents of commitment (Mathieu, 1991; Mathieu \& Zajac, 1990) - age, tenure, autonomy, and role ambiguity, for example - can be understood as intervening variables that channel the occurrence and strength of different commitments. In order to "manage commitment," we have to know which constellation of different objects, loci, bases, and foci of commitment are related to which source of commitment and how tangible their interrelations are. In this way we can create different commitments for different organizational purposes. These purposes can be refined as the consequences of commitment, such as turnover, job performance, and different normative characteristics of organizational behaviour (Wiener, 1982).

\section{Organization culture}

In a fundamental sense, a culture exists when people come to share a common frame of reference for interpreting and reacting towards one another and towards the world in which they live. This common frame of reference includes language, values, beliefs and interpretation of experiences. It is reflected in customs, folkways, communication and observable 
features of the community including rituals, rites, celebrations, legends, myths and heroic saga.

A surprising aspect of the recent rise in interesting organization culture is that the concept, unlike virtually every other concept in the field, has no single widely accepted definition. Indeed, it often appears that authors feel compelled to develop their own definitions, which range from very broad to highly specific. For example, Deal and Kennedy (1982) define a firm's culture as "the way we do things around here." This very broad definition presumably could include the way a firm manufactures its products, pays its bills, treats its employees, and performs any other organizational operations. More specific definitions include those of Schein (1985) as "the pattern of basic assumptions that a given group has invented, discovered, or developed in learning to cope with its problems of external adaptation and internal integration", and Peters and Waterman's (1982) as “a dominant and coherent set of shared values conveyed by such symbolic means as stories, myths, legends, slogans, anecdotes, and fairy tales". Table 2 lists other important definitions of organization culture.

\section{How visible are the organizational cultures?}

Among the best-known representations of organizational culture are Hofstede's (1994) 'Onion Diagram' subtitled 'manifestation of culture at different levels of depth' and Schein's (1992) 'levels' of culture. Each emphasizes that organizational cultures manifest themselves in many ways. Some of these are visible and therefore easy to discern when studying organizations but because of their shallow or superficial nature, the true meaning is difficult to decipher. These manifestations are Hofstede's 'symbols', 'heroes', and 'rituals' and Schein's 'artifacts' (see Fig 1). By changing these visible practices and artifacts they are able to effect a culture change. Unfortunately, for real change the process also needs to occur far more deeply, in the less visible levels.

The deepest levels of culture (Hofstede's 'values' and Schein's 'basic underlying assumptions') are invisible and as a consequence, extremely difficult to discover. They provide what Argyris (1995) terms as 'the theories in use' upon which the more visible 'practices' or 'artifacts' of organizational culture are built. Hofstede refers to these values as 'core of culture'. Such values are likely to have become so taken for granted that there will be little variation in them within a culture or subculture, (Schein 1992). They will be communicated to new employees, thereby transferring the culture. If these basic underlying assumptions are strongly held then group members will find behaviours on any other premise inconceivable. For this reason changing these is likely to result in a true culture change which will also be reflected in 'practices' and 'artifacts'. However because they are deeply and strongly held in the individual's subconscious, they are extremely difficult to change. Between the deepest and the shallowest levels Schein (1992) introduces 'espoused values'. These are values connected with moral and ethical codes and determine what people think ought to be done, rather than what they necessarily do. Often organization represents a particular view of their culture through formal documents, such as annual reports, mission statements or speeches by senior managers, which comprise these espoused values.

Table 2. Important definitions of Organization Culture

\footnotetext{
“A belief system shared by organization's members" (Spender, 1983).

"Strong widely held core values" (O'Reilly, 1993).

"The collective programming of the mind" (Hofstede, 1980).

"A set of symbols, ceremonies, and myths that communicates the underlying beliefs and values of that organization to its employees" (Ouchi, 1980).

Porter, Lawler \& Hackman (1975) identify organization culture as, "a set of customs and typical patterns of ways of doing things. The force, pervasiveness and nature of such model, beliefs and values vary considerably from organization to organization. Yet it is assumed that an organization that has any history at all has developed some sort of culture and that this will have a vital impact on the degree of success of any effort to improve or alter the organization.

Daniel R. Denison (1990) defines, "Organization culture refers to the underlying values, beliefs and principles that serve as a foundation for organization's management systems, as well as the set of management practices and behaviors that both exemplify and reinforce those basic principles."

Kono and Clegg (1998) show five elements of culture - values, decision-making patterns, behaviour patterns, performances, and rewards - as interacting through feedback loops comprising intrinsic and extrinsic rewards.
} 


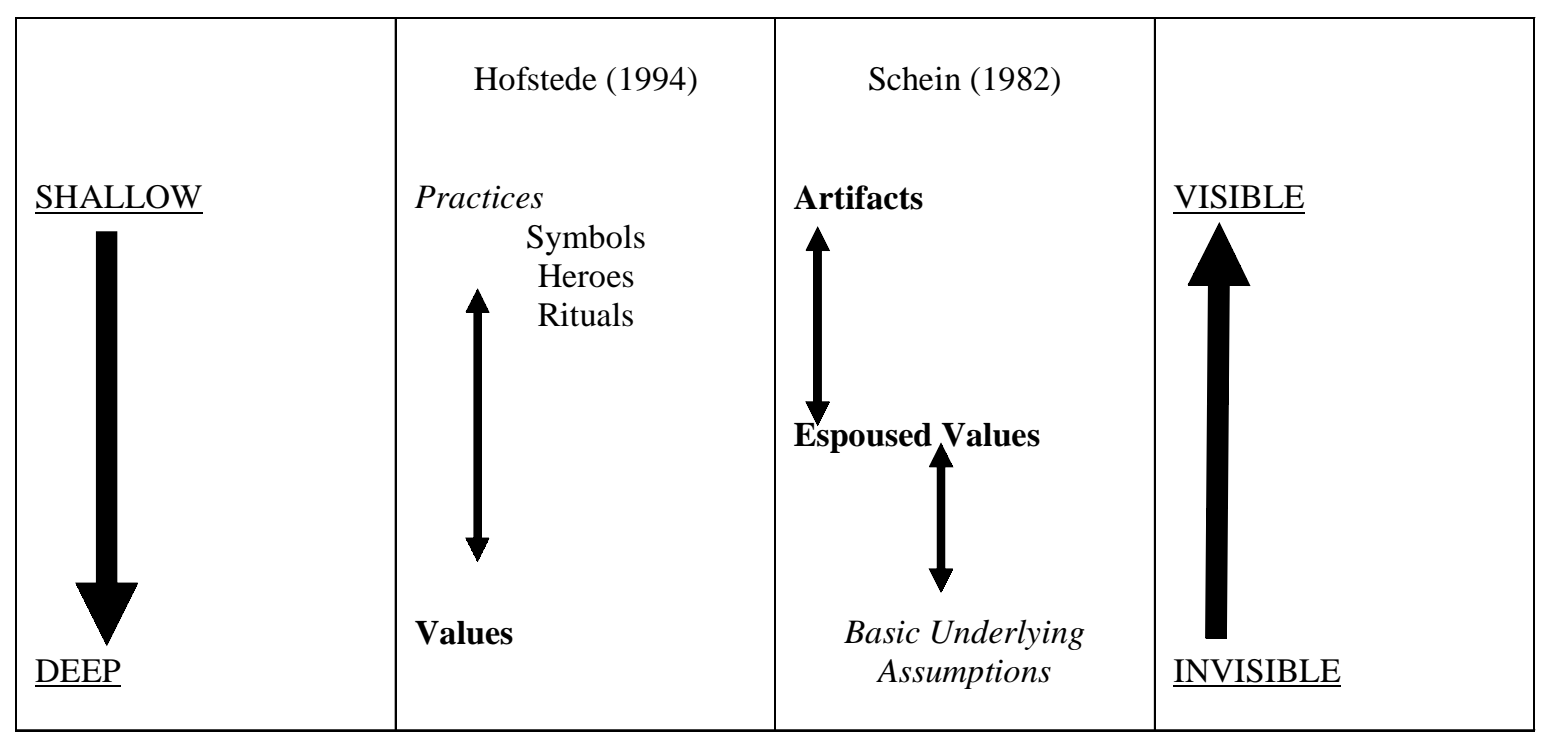

Fig 1. A Comparison of Hofstede's and Schein's representation of Organization Culture

\section{Strength of culture as strength of commitment}

A strong culture is usually understood as a synonym for consistency: Beliefs and values are "shared relatively consistently throughout an organization" (Brown, 1995). In the language of commitment, consistency of culture is the social symmetry of objects, bases, foci, and consequences of commitment. Without social symmetry, strong individual commitment is not the same as strong organizational culture. A strong culture is often seen to enable an organization to achieve excellent performance, a hypothesis that has been made by Deal and Kennedy (1982).

Strength of culture can be easily conceptualized as strength of commitments and the optimal degree of their social symmetry. This points out that even though the culture is holistic, it exists only in social relationships, which, in turn, can be strengthened by commitments. Brown (1995) differentiates between two kinds of mechanisms for managing culture: those relying on human resources instruments and those involving leader action and inaction. Among the former are the recruitment and selection procedures, induction, socialization and training, performance appraisal systems, and reward systems. Among the latter are management by symbols (use of time, language, meetings, agendas and minutes, physical settings) and management by rites of passage, enhancement, degradation, conflict resolution, integration, and renewal. All of these can be understood as the targets of management of commitment. Management of commitment is also the management of culture, because it is commitment that binds people to organizational ideas and agents.
Managers can affect organizational commitment by learning to use antecedents of organizational commitments. Company tenure, union satisfaction, job satisfaction, job involvement, job equity and supervisor support have been shown to be significant predictors of company commitment (Johnson \& Jones-Johnson, 1992). Team cohesion, task challenge, supervisory behaviour, and organizational climate can also be predictors, but in different ways in different career stages (Brooks \& Steers, 1991). Role strain (role ambiguity, role conflict, role overload), training characteristics, and achievement motivation are also important antecedents of commitment (Mathieu, 1991). The specially designed fit between individuals' preferences and organizational culture can be seen as a goal of commitment, because both job satisfaction and organizational commitment can be predicted with this fit (O'Reilly, Chatman, \& Caldwell, 1991). These regularities are not structured to support management of climate and culture directly, but there is no obstacle preventing researchers from doing quantitative and qualitative research and reconceptualising the antecedents and consequences of commitment.

\section{The present study}

\section{Objectives}

1. To examine the relationship between the variables of organizational culture and organizational commitment.

2. To determine the extent to which the dimensions of organizational commitment would be predicted by the dimensions of organizational culture. 


\section{Hypotheses}

A set of null hypotheses was generated for the present study:

1. There will be no relationship between Purpose (one of the variables of organization culture) and organizational commitment.

2. There will be no relationship between Structure (one of the variables of organization culture) and organizational commitment.

3. There will be no relationship between Leadership (one of the variables of organization culture) and organizational commitment.

4. There will be no relationship between Relationship (one of the variables of organization culture) and organizational commitment.

5. There will be no relationship between Rewards (one of the variables of organization culture) and organizational commitment.

6. There will be no relationship between Helpful Mechanisms (one of the variables of organization culture) and organizational commitment.

\section{Sample}

The sample consisted of 382 respondents in five different automobile companies. The sample consisted of managers, executives, and supervisors from all the major departments of the companies, namely, Personnel, Engineering, Production, Marketing, and Maintenance, etc. Average age and the tenure of the respondents were 39 and 12 years respectively. 86 out of 382 respondents were females.

\section{Instruments and measures}

\section{(i) Measure of Organizational Culture}

For the purpose of measuring the organizational culture, the Organizational Diagnosis Questionnaire by Robert C. Preziosi was used. The purpose of ODQ is to provide survey feed back data for intensive diagnostic efforts. Use of questionnaire either by itself or in conjunction with other measures provides the data needed for studying the functioning of an organization and/or its sub-parts. ODQ is based on Weisbord's practitioner-oriented theory (1976). It provides for assessment in six areas of formal and informal activity. The scale had 18 items.

1) Purpose (PUR): The items focused on the issues of the awareness and the basic clarity and agreement about the goals/purpose of the organization.

2) Structure (STR): The items focused on the ways the work has been divided in the organization and the extent to which it is instrumental in achieving the objectives of the organization.

3) Leadership (LED): Items relate to the ways in which superiors / leaders function in an organization and to what degree they can influence their subordinates.

4) Relationship (RLS): Items focus on the ways employees relate themselves to other colleagues, superiors and technologies.

5) Rewards (REW): Items focus on the issue of linkage of incentives with one's performance in the organization.

6) Helpful Mechanisms (HMS): Items relate to the availability of adequate coordinating technologies in the organization, which act as a direction for growth and development.

\section{(ii) Measure of Organizational Commitment}

The scale used for the purpose of measuring Organizational Commitment of the employees was the one developed by Buchanan (1974).

Buchanan views commitment as a "partisan, affective attachment to the goals and values of an organization, to one's role in relation to goals and values and to the organization for its own sake, apart from its purely instrumental worth". The concept is therefore measured through three components.

a) Job Identification (J Iden) is viewed as "adopting as one's own the goal and values of the organization". It is tapped through six items.

b) Job Involvement ( J Inv) is measured through five items. These are intended to measure, "psychological immersion or absorption in the activities of one's work role"

c) Organizational loyalty (O Loy) is a response that tries to "tap the feelings of affection and attachment to the organization," and is measured with the help of seven items.

The 18-item scale contained five reversed score items, Buchanan obtained responses from 279 managers from eight organizations and coefficient alphas of 0,86, $0,84,0,92$ and 0,94 were recorded for the three subscales and the total scale respectively. The Sub-scales were found to be Inter co-related. The correlation between Identification and Involvement was 0,65, between Identification and Loyalty was 0,74 , and between Involvement and Loyalty was 0,58. 


\section{Analysis of the data}

After scoring the questionnaire, the raw data was tabulated for each variable being studied. The computation of the raw data was done in order to do the following statistical analysis:

1) Correlational analysis,

2) Multiple Regression Analysis.

1. Correlational Analysis - In order to understand the relationship of causal variables i.e. organization culture and the outcome variables i.e. job identification, job involvement and organizational loyalty, the Pearson's product-moment correlation was computed.

2. Multiple Regression Analysis - Regression is the determination of statistical relationship between two or more variables. The dimensions of organizational commitment were taken as dependent or criterion variables, and the dimensions of organizational factors were taken as independent or predictor variables. The stepwise Multiple Regression was used.

\section{Results}

Table 3 shows the Pearson product-moment correlation between the dimensions of organization culture and organizational commitment.
As can be seen from Table 3, the relationships between the dimensions of organization culture and the dimensions of organizational commitment are positive. Most of the dimensions of organization culture were found to be significantly positively related to the dimensions of organizational commitment. Therefore the null hypotheses from 1-6 were rejected and the alternate hypotheses that there is a significant relationship between the variables of organizational culture and the variables of organizational commitment are accepted.

Job identification was significantly positively related to all the six dimensions of organization culture namely, purpose, structure, leadership, relationship, reward and helpful mechanisms. Job involvement was significantly related to all the dimensions of culture except structure. Organizational loyalty was also significantly positively related to all the dimensions of culture except structure.

Table 4 shows the results of Multiple Regression Analysis with the criterion variable of organizational commitment and the predictor variables of organization culture.

The results of the multiple regression analysis are shown in Table 4. The variables which were entered

Table 3. Coefficient of correlation between the dimensions of organization culture and organizational commitment

\begin{tabular}{|c|l|c|c|c|}
\hline S. No. & \multicolumn{1}{|c|}{ Organizational Factors } & Job Identification & Job Involvement & $\begin{array}{c}\text { Organizational } \\
\text { Loyalty }\end{array}$ \\
\hline 1 & Purpose & $.65^{* *}$ & $.48^{* *}$ & $.56^{* *}$ \\
\hline 2 & Structure & $.40^{*}$ & .22 & .33 \\
\hline 3 & Leadership & $.49^{* *}$ & $.51^{* *}$ & $.46^{* *}$ \\
\hline 4 & Relationship & $.51^{* *}$ & $.53^{* *}$ & $.48^{* *}$ \\
\hline 5 & Reward & $.45^{* *}$ & $.44^{*}$ & $.46^{* *}$ \\
\hline 6 & Helpful Mechanisms & $.64^{* *}$ & $.41^{*}$ \\
\hline $\begin{array}{l}* \\
* * \text { Significant at .01 level }\end{array}$ & & \\
\hline
\end{tabular}

Table 4. Predicting the dimensions of organizational commitment from the dimensions of organization culture

\begin{tabular}{|l|c|c|c|c|c|c|c|c|}
\hline Criterion Variable & \multicolumn{9}{|c|}{ Beta Values $(\beta)$} & \multirow{2}{*}{ AR $^{2}$} & \multirow{2}{*}{ F value $^{*}$} \\
\hline & PUR & STR & LED & RLS & REW & HMS & & \\
\hline Job Identification & $.27^{\mathrm{b}}$ & -05 & .14 & .17 & .18 & $.30^{\mathrm{b}}$ & .64 & 22.19 \\
\hline Job Involvement & .06 & -.01 & .11 & $.41^{\mathrm{a}}$ & .05 & .09 & .29 & 17.21 \\
\hline $\begin{array}{l}\text { Organizational } \\
\text { Loyalty }\end{array}$ & $.59^{\mathrm{a}}$ & .20 & .11 & .08 & $.30^{\mathrm{b}}$ & .04 & .58 & 11.99 \\
\hline $\begin{array}{l}\text { a- significant at .01 level } \\
\text { b- significant at .05 level }\end{array}$ & & & & & & & \\
\hline
\end{tabular}


into the model were the six dimensions of organizational culture comprising purpose, structure, leadership, relationship, rewards and helpful mechanisms to predict different dimensions of organizational commitment. The Table shows the beta weights assigned to each variable (which indicates the magnitude of each variable's contribution to explained variance), the adjusted explained variance $\left(\mathrm{AR}^{2}\right)$, and the $\mathrm{F}$ value for each of the organizational commitment indices.

The point to note from Table 4 is that the model explains a significant amount of variance in most of the dimensions of organizational commitment. Though all the dimensions did not enter in the model to predict the criterion variables but some of the dimensions made a significant contribution to predicting organizational commitment. Purpose and helpful mechanisms, the dimensions of organizational culture, explained Job identification (64\% of the variance). Job involvement (29\% of the variance) was explained by relationship. Purpose and rewards, the dimensions of organizational culture, explained organizational loyalty (58\% of the variance).

\section{Discussion}

When the organizational factors were regressed to predict job identification, job involvement, and organizational loyalty, it was found that purpose, rewards, and helpful mechanisms were contributing significantly to predict organizational commitment. Kagan (1958) proposed that attachment to an object, individual, group, or organization results from the identification with the values, attitude or goals of the model and their incorporation into the cognitive response set of individuals. The degree to which an individual identifies with a model may vary with the reasons for this attachment and its manifestations. Thus, although organizational commitment has often been used in a global way to encompass antecedent processes and consequences of attachment felt for the organization, it will reflect the degree to which the individual internalizes or adopts characteristics or perspectives of an organization.

Additionally, another independent variable namely, Helpful Mechanisms also contributed to the above said factors. If the employees of an organization perceive that the system is providing them with adequate support in terms of resources and coordinating technologies, they may develop a sense of involvement and loyalty to the organization. The above findings could be explained with the help of the model evolved by Malhotra (1985) wherein, he suggested, that an in- dividual's degree of involvement with the job is the function of perceived variety, challenge and autonomy of the job, perceived influence and specific satisfaction in the organization which includes satisfaction with salary and other helpful mechanisms, supervisory behaviour and relationships. Mahlon (1990) has also discussed about 'alternative work places' which would be characterized by features as commitment, informational, open culture and proactive management, availability of helpful mechanisms, a 'push-back' approach and clear links between staff, function and time.

Among other organizational factors, reward contributed positively to predict organizational loyalty. In one of the studies Oliver Nick (1990) examined the influence of employee's work values, demographic characteristics and organizational rewards on levels of organizational commitment, involvement, identification and loyalty in a UK employee owned firm and found that organizational rewards showed a significant relationship with job identification and involvement. The results of the present study are in consonance with these findings.

\section{Implications and conclusions}

These findings carry a number of implications for research and practice in the area of commitment and organization culture. The main issue that emerges from this study is that the importance of organization culture in understanding organizational commitment can never be underestimated nor overlooked - organization culture is central to any activity in the organization. Though this study is an industry specific study, focusing on Automobile Industry but the findings can be generalized to any organization or industry.

Since culture is such a crucial factor in the long-term effectiveness of organizations and has impact on the working environment, as well as the individuals working in it, and therefore on their commitment levels, it is imperative that those charged with managing culture be able to identify the dimensions of culture and to develop a strategy for changing it. The dependence of organizational commitment on culture is due to the fact that when the values, orientations, definitions, and goals stay constant - even when procedures and strategies are altered - organizations return quickly to status quo. The same is true for individuals. Personality types, personal styles, and behavioral habits rarely change significantly, despite programs to induce changes such as diet, exercise regimen, or charm schools. Without an alternation of the fundamental goals, values, and expectations of 
organizations or individuals, change remains superficial and short-term in duration. Modifying organizational culture, in other words, is a key to the creation of organizational commitment in the organizations, which will also help in the adaptation to the increasing turbulent environment faced by these modern organizations.

Commitment is broadly understood to comprise only the base of commitment and focus of commitment. The content of these concepts is too simple to cover culturally relevant issues in organizational studies. One reason for this is probably the predominantly quantitative techniques of commitment studies. The conceptual reasoning has been oriented to develop better survey measures of commitment, not to broaden theoretical instrument. These are needed to make the nature of the binding force of commitment more evident.

The distinction between commitment and idea, commitment and agent, along with ensuing distinctions in objects of commitment would broaden the scope of studies of organizational commitment.

The inherently social nature of organizational commitment is often forgotten when commitment is understood as the psychological state of mind of an individual. Research on organizational culture has challenged this by emphasizing social relations as determinants of individual meanings. Aggregation of individual perceptions of an entire organization is not enough. A more multi-dimensional analysis of commitments in organizations opens up a research field where commitments can be approached more qualitatively, both as instruments and constituents of organizational culture.

Conclusions of this study are limited by the respondents being only from one industry i.e., automobile industry and reliance on self-reported cross-sectional data. Though most of the organizational factors contribute to predict the dimensions of organizational commitment but it is possible that the variables, which did not contribute directly, may have had indirect connection, which was mediated by other variables.

\section{References}

ALLEN, N. J. \& MAYER, J. P. (1990) The Measurement of Antecedents of affective, continuance and normative commitment to the organization. Journal of Occupational Psychology 63: 1-18.

ARGYRIS, C. (1995) Action Science and Organizational Learning Journal of Managerial Psychology 10 (6): 20-26, 60-69.
APGAR, M. (1998) The Alternative work Place: Changing where and how people work. Harvard Business Review. May-June: 121-136.

BECKER, H. S. (1960) Notes on the concept of commitment. American Journal of Sociology 66: 32-40.

BROOKS, J. L. \& STEERS, A. (1991) Predictors of Organizational Commitment: Variation across Career Stages. Journal of Vocational Behaviour 38: 53-64.

BROWN, A. (1995) Organizational Culture. London: Pitman.

BUCHANAN, B. (1974) Building organizational commitment: The socialization of managers in Work organizations. Administrative Science Quarterly 19: 533-546.

DEAL, T. E. \& KENNEDY, A. A. (1982) Corporate Culture: The Rites and Rituals of Corporate Life, Readings, Mass: Addison - Wesley.

DENISON, D. R. (1990) Corporate culture and organizational effectiveness. New York: John Wiley.

Evidence from the U. K. Human Relations 43(6): 513526.

HOFSTEDE, G. (1980) Cultures Consequences: International Differences in Work Related Values, Beverly Hills, Calif: Sage.

HOFSTEDE, G. (1994) Cultures and Organizations: Software of the Mind: Intercultural Cooperation and its Importance for Survival. London: Harper Collins.

JOHNSON, W. R. \& JONES-JOHNSON, G. (1992) Differential predictors of union and company commitment: Parallel and divergent models. Psychology 29: 1-12.

KANTER, R. M. (1968) Commitment and Social Organization: A Study of Commitment Mechanisms in Utopian Communities. American Sociological Review 33: 497-517.

KELMAN, H. C. (1958) Compliance, identification and internalization: Three processes of Attitude change. Journal of Conflict Resolution 2: 51-60.

KAGAN, J. (1958) The Concept of Identification. Psychological Review 65: 296-305.

KONO, T. \& CLEGG, S. R. (1998) Transformation of corporate culture: Experiences of Japanese Experiences. New York: Walter de Gruyter.

MALHOTRA, A. (1985) Value erosion and Managerial Alienation in Indian Organizations. Business India: 14-27.

MATHIEU, J. E. \& ZAJAC, D. M. (1990) A review and meta - analysis of the antecedents, correlates, and consequences of organizational commitment. Psychological Bulletin 108: 171-194.

MATHIEU, J. E. (1991) Across-level of nonrecursive model of the antecedents of organizational commitment and satisfaction. Journal of Applied Psychology 76: 607-618. 
MEYER, J. P. \& ALLEN, N. J. (1997) Commitment at Workplace: Theory, Research and Application. Thousand Oaks, CA: Sage.

MORROW, P. C. (1983) Concept redundancy in organizational research: the case of work commitment. Academy of Management Review 8: 486-500.

NICK, Oliver. (1990) Work rewards, Work values and Organizational commitment in an employee-owned firm: Evidence from the U.K. Human Relations 43: (6): 513-526.

O'REILLY, C. A. \& CHATMAN, J. A. (1986) Organizational commitment and psychological attachment: The effect of compliance, identification, and internalization on prosocial behaviour. Journal of Applied Psychology 71: 492-499.

O'REILLY, C. A.; CHATMAN, J. A. \& CALDWELL, J. A. (1991) People, jobs and organizational culture. (Working paper). Berkley: University of California.

O'REILLY BRIAN (1993) Secrets of Most Admired Corporations: New Ideas and New Products, Fortune March 3: 60-64.

OUCHI, W. G. (1980) Theory Z: How American Business meets the Japanese Challenge. Readings, Mass: Addison-Wesley.

PETERS, T. \& WATERMAN, R. H. (1982) In Search of Excellence, London \& New York: Harper \& Row.

PORTER, L. W.; STEERS, R. M. \& MOWDAY, R. T. (1974) Organizational commitment, job satisfaction, and turnover among psychiatric technicians. Journal of Applied Psychology 59: 603-609.

PORTER, L. W.; LAWLER, E. E.; HACKMAN, J. R. (1975) Behaviours in Organization', New York, McGraw Hill.

REICHERS, A. E. (1985) A review and reconceptualization of organizational commitment. Academy of Management Review 10: 465-476.

SCHEIN, L. H. (1985) Organizational Culture and Leadership: A Dynamic View. San Francisco: Jossey - Bass: 45-61.

SCHEIN, E. H. (1992) Organizational Culture and Leadership, $2^{\text {nd }}$ edition, San Francisco: Jossey Bass.

SPENDER, J. C. (1983) Myths, Recipes \& Knowledge in Organizational Analysis. Unpublished manuscript, Graduate School of Management, UCLA.

VIRTANEN, T. (2000) Commitment and the study of organizational climate and culture, in Handbook of Organizational Climate and Culture by Ashkanasy, N. M., Wilderom, C. P. M., \& Peterson, M. F. Sage Publications, Inc.: 41-50.

WIENER, Y. (1982) Commitment in organizations: A normative view. Academy of Management Review 7: 418-428.

WEISBORD, Marvin R. (1976) Organizational Diagnosis: Six places to look for trouble with or without a Theory, Group and organizational studies 1(4): 430-477. 